\title{
Experimental study on fast pyrolysis of free-falling millimetric biomass particles between $800{ }^{\circ} \mathrm{C}$ and $1000^{\circ} \mathrm{C}$
}

\author{
Li Chen ${ }^{\mathrm{a}}$, Capucine Dupont ${ }^{\mathrm{a}, *}$, Sylvain Salvador ${ }^{\mathrm{b}}$, Maguelone Grateau ${ }^{\mathrm{a}}$, Guillaume Boissonnet ${ }^{\mathrm{a}}$, \\ Daniel Schweich ${ }^{c}$
}

${ }^{a}$ CEA Grenoble, DRT/LITEN/DTBH/LTB, 17 rue des Martyrs, 38054 Grenoble, France

${ }^{\mathrm{b}}$ Centre RAPSODEE, UMR 5302 CNRS Mines Albi-Carmaux, Campus Jarlard, route de Teillet, 81013 Albi, France

${ }^{c}$ LGPC - CNRS/CPE Lyon, 43, bd du 11 novembre 1918, BP 82077, 69616 Villeurbanne, France

\author{
Keywords: \\ Biomass \\ Fast pyrolysis \\ Drop tube \\ Particle size \\ Kinetics
}

\section{H I G H L I G H T S}

Drop tube pyrolysis was tested at $800{ }^{\circ} \mathrm{C}$ and $950{ }^{\circ} \mathrm{C}$ on 350 to $800 \mu \mathrm{m}$ wood particles.

- Solid size impacts pyrolysis time and char structure but not final products yields.

- Temperature significantly changes individual gas species yields.

- Particle shrinkage can be observed along pyrolysis under all conditions tested.

\begin{abstract}
A B S T R A C T
Pyrolysis experiments were performed between $800^{\circ} \mathrm{C}$ and $950^{\circ} \mathrm{C}$ on wood particles with diameters from 350 to $800 \mu \mathrm{m}$ in a lab-scale drop tube reactor to reproduce surface heat flux representative of gasifiers conditions. It was shown that particle size affected the required pyrolysis time but changed neither gas/tar/char mass yields nor composition of the products at the end of pyrolysis. The initial particle size also affected the resulting char morphology: the larger the biomass particles, the more fibrous the char. Temperature had influence neither on gas/tar/char mass yields nor on gas and solid elemental composition at the end of pyrolysis, but significantly changed the yields of individual gas species. Whatever the conditions tested, a significant shrinkage could be observed on particles during pyrolysis. These experimental results confirm the strong coupling between chemical reactions, particle geometrical properties and heat transfers during pyrolysis under these conditions.
\end{abstract}

\section{Introduction}

In recent years, there has been a growing interest worldwide in gasification of lignocellulosic biomass such as forestry and agricultural residues into syngas $\left(\mathrm{H}_{2}, \mathrm{CO}\right)$. This syngas can then be transformed into various end-use products such as liquid fuels (Biomass-to-Liquid process) or gaseous fuels (Synthetic Natural Gas). The development of the gasification process requires models that are able to predict products yields and kinetics versus operating conditions. In particular, the first step of gasification, namely pyrolysis, is of great importance since more than $80 \%$ of initial sample mass can be converted into volatiles during this step. It is well-known that the kinetic rate and product distribution of pyrolysis vary drastically with the operating conditions, notably tem-

\footnotetext{
* Corresponding author. Tel.: +33 438780205.

E-mail address: capucine.dupont@cea.fr (C. Dupont).
}

perature, external heat flux transferred to solid, initial particle size, and solid/gas residence time.

As shown in the very complete review made by Di Blasi [1], modeling of the pyrolysis of a biomass particle has been the subject of very extensive literature since the fifties. Very complex models have been developed to describe this system. However, at the moment, they still suffer from limitations. Those are mainly related to the lack of experimental input/output data under conditions representative of industrial gasifiers (temperature higher than $800{ }^{\circ} \mathrm{C}$; high heat flux at solid surface in the range $105-106 \mathrm{~W} \mathrm{~m}^{-2}$ ) regarding the evolution of solid properties during conversion and the kinetic parameters and heat of the chemical reactions, as well as products yields. Thermogravimetric Analysis (TGA) has been widely used for studying the kinetic and product yields of biomass pyrolysis, and numerous examples are available in the literature [2,3]. However, the applicability of the TGA results obtained at low heating rate to high temperatures and heat fluxes 


Nomenclature
$\begin{array}{llll}\text { w\% } & \text { mass percent } & & \\ \text { wmf\% } & \text { mass percent on moisture-free basis } & \text { GC } & \text { Gas Chromatograph } \\ \text { wmaf\% } & \text { mass percent on moisture-ash-free basis } & \text { IR } & \text { Infra Red } \\ & & \text { SEM } & \text { Scanning Electron Microscopy } \\ \text { Acronym } & \text { STP } & \text { Standard Temperature and Pressure } \\ \text { DTR } & \text { Drop Tube Reactor } & \text { TCD } & \text { Thermal Conductivity Detector } \\ \text { FID } & \text { Flame Ionization Detector } & \text { TGA } & \text { Thermogravimetric Analysis }\end{array}$

typical of gasifiers is questionable. Lab-scale Drop Tube Reactor (DTR), sometimes also called free fall reactor or entrained flow reactor, is a good apparatus to reproduce the heat fluxes encountered in industrial gasifiers such as fluidized-bed or entrained flow reactors. In recent years, it has been used by some researchers for studying biomass pyrolysis behavior. Most researches were focused on final mass yields of total gas and solid [4-10]; few on tar yields $[8,11]$. Char morphology evolution $[8,9,12,13]$ has also been investigated sometimes, as well as pyrolysis kinetics [12]. None of these works has made an extensive study of the particle size influence.

The purpose of this work is to complete the existing set of experimental data on fast pyrolysis for further use in gasification models. Hence, pyrolysis experiments were performed on wood particles of various sizes $(350-800 \mu \mathrm{m})$ at high temperature $\left(800^{\circ} \mathrm{C}\right.$ and $\left.950^{\circ} \mathrm{C}\right)$ in a drop-tube furnace to get information on products yields and char morphology along time under high heat flux representative of gasifiers.

\section{Materials and methods}

\subsection{Biomass feedstock}

Particles of beech were sieved to obtain four samples with relatively uniform particle sizes covering the range 350-800 $\mu \mathrm{m}$ (Table 1). Due to the fiber-rich structure of wood, the wood and char particles are flake-like or cylinder-like rather than near-spherical. Thus their size can only be roughly characterized by sieving. For a better approximation of the particle size, the three dimensions - length, width and thickness - were measured in order to calculate the equivalent spherical diameter $d_{\mathrm{es}}$ through the following equation:

$d_{\mathrm{es}}=\left(\frac{6 \mathrm{~L} \mathrm{~W} \mathrm{~T}}{\pi}\right)^{1 / 3}$

Table 1

Beech sample size classification.

\begin{tabular}{lll}
\hline $\begin{array}{l}\text { Sample } \\
\text { name }(\mu \mathrm{m})\end{array}$ & $\begin{array}{l}\text { Particle size }(\text { sieve } \\
\text { classification })(\mu \mathrm{m})\end{array}$ & $\begin{array}{l}\text { Average equivalent diameter } \\
(\text { standard deviation })(\mu \mathrm{m})\end{array}$ \\
\hline 350 & $100-313$ & $340( \pm 40)$ \\
500 & $400-500$ & $520( \pm 30)$ \\
700 & $630-710$ & $690( \pm 30)$ \\
800 & $800-900$ & $790( \pm 40)$ \\
\hline
\end{tabular}

For the particle length and width (defined as the two largest dimensions), measurements were performed through images of 25 particles sampled among each size range. The uncertainty was estimated to be of about $\pm 50 \mu \mathrm{m}$. The particle thickness was measured by a vernier caliper. It was found to be in the range of $\pm 50 \mu \mathrm{m}$ around the average value. The equivalent diameter was then calculated as the average of the results obtained for all the particles sampled. As shown in Table 1, the standard deviation was found to be smaller than $40 \mu \mathrm{m}$, which indicated a relatively narrow distribution of equivalent diameters inside the same sample.

Regarding the proximate and ultimate analyses, no significant differences could be observed between the four samples with different sizes. Hence, only one set of values is given for all samples in Table 2. The particle density was measured as $710 \pm 35 \mathrm{~kg} \mathrm{~m}^{-3}$.

\subsection{Drop tube experiments}

The Drop Tube Reactor (DTR) used in this work is depicted in Fig. 1. It was described in detail and characterized in several previous studies, in particular $[14,15]$. Briefly, it consists of an alumina tube of $2000 \times 75 \mathrm{~mm}$ (length $\times$ internal diameter), inserted in a vertical electrical heater with three independent heating zones; the isothermal reaction zone is $1 \mathrm{~m}$ long.

Wood particles were continuously fed by a controlled weighing system at a flow rate of $0.5 \mathrm{~g} \mathrm{~min}^{-1}$ and injected into the reactor with a $2 \mathrm{~L} \mathrm{~min}^{-1}$ (at STP) transport nitrogen stream through a water-cooled feeding tube. A dispersion dome was placed at the outlet of the feeding tube to distribute the solid particles homogeneously over the reactor cross section. Another main nitrogen stream passed through a pre-heater to reach the reactor temperature and then met the mixture of cold wood particles and transport nitrogen stream at the dispersion dome. The total nitrogen flow rates were $18.8 \mathrm{~L} \mathrm{~min}^{-1}$ and $16.5 \mathrm{~L} \mathrm{~min}^{-1}$ (STP) for the experiments at $800^{\circ} \mathrm{C}$ and $950^{\circ} \mathrm{C}$ respectively, in order to keep the same gas velocity. A water-cooled sampling probe was inserted from the bottom of reactor to collect gas and particles. The residence length, which is the distance between the bottom of the feeding tube and the top of the sampling probe, could be changed so as to change the residence time of solid and gas. A representative fraction of the exhaust gas was sucked in the sampling probe to pass through a solid collection pot and a filter. Then a part of the gas was analyzed by several gas analyzers (IR, FTIR, micro-GC, FID, mirror hygrometer, TCD). Each main gaseous component (except water vapor) was

Table 2

Proximate and ultimate analyses of the beech sample.

\begin{tabular}{|c|c|c|c|c|c|c|c|c|}
\hline \multicolumn{4}{|c|}{ Proximate analysis } & \multicolumn{5}{|c|}{ Ultimate analysis } \\
\hline Moisture (w\%) & Volatile matter (wmf\%) & Fixed carbon (wmf\%) & Ash (wmf\%) & $C($ wmaf\%) & $\mathrm{H}($ wmaf\%) & $\mathrm{N}$ (wmaf\%) & S (wmaf\%) & O (wmaf\%) \\
\hline 6.9 & 85.3 & 14.3 & 0.4 & 49.2 & 6.0 & 0.5 & 0.02 & 44.3 \\
\hline
\end{tabular}




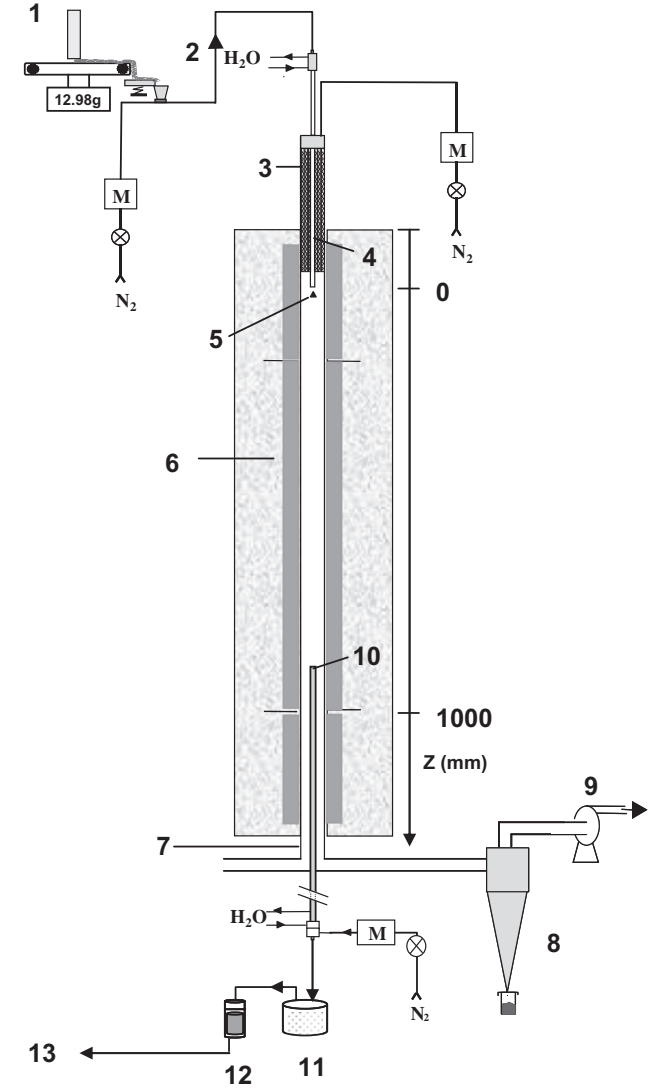

$\begin{array}{ll}\text { 1- controlled weighing system } & \text { 8- cyclone collector } \\ \text { 2- pneumatic transport } & 9 \text { - exhaust fan } \\ \text { 3- electrical preheater } & 10 \text { - water cooled sampling probe } \\ \text { 4- water cooled feeding tube } & \text { 11- solid collection pot } \\ \text { 5- dispersion dome } & \text { 12- filter } \\ \text { 6- three-zone electrical furnace } & \text { 13- to gas analysers } \\ \text { 7- } 75 \mathrm{~mm} \text { i.d. alumina tube reactor } & \text { M- mass flow meter and controller }\end{array}$

Fig. 1. Schematic diagram of DTR.

measured by at least two different analyzers and it was found that the relative differences among the results given by different analyzers were lower than $5 \%$. Moreover, the repeatability of the results was checked by performing the same test three times on different days. The relative differences among the three tests were always smaller than $5 \%$ for all product yields except for water vapor. The high uncertainty of the value given by mirror hygrometer (up to $20 \%$ of the absolute value) might be due to the fact that the mirror surface could be contaminated by the condensed components in the released gas.

Several analyses were conducted on the particles recovered in the solid collection pot:

- Ultimate analysis to determine the elemental composition in C, $\mathrm{H}$ and $\mathrm{O}$.

- Ash content measurement: the ash tracer method was used to calculate the solid mass yields as detailed in [16].

- Observation of structure through a Scanning Electron Microscopy (SEM) device.

Due to the lack of direct measurement, the tar yield was deduced from the difference between the injected virgin wood mass and the sum of the masses of collected gas and solid residue.

\section{Results}

\subsection{Solid, total gas and tar yields}

The yields of solid residue, gas and tar versus residence length are shown in Fig. 2. Note that the term "solid residue" in the present work corresponds to the sum of unreacted wood and produced char. The relative uncertainty is estimated to be of $10 \%$ for the gas yield and of $10-20 \%$ for the solid residue yield. The uncertainty is not plotted for figure clarity.

Firstly, as shown in Fig. 2a, at $800{ }^{\circ} \mathrm{C}$, when the residence length increases from 0.3 to $0.9 \mathrm{~m}$, three different pyrolysis progress levels could be observed for the different particle sizes:

- For the sample of $350 \mu \mathrm{m}$, the yields of solid residue, gas, and tar almost remain constant. This indicates that the pyrolysis is already finished within a residence length of $0.3 \mathrm{~m}$.

- For the sample of $500 \mu \mathrm{m}$, the yield of solid residue slightly decreases from 10 to $6 \mathrm{w} \%$. The yield of gas significantly increases from 63 to $83 \mathrm{w} \%$ and the deduced yield of tar significantly decreases from 27 to $11 \mathrm{w} \%$. This indicates that wood devolatilization is almost finished at a residence length of $0.3 \mathrm{~m}$, while cracking reactions of primary tar produced by wood devolatilization are still in progress with the increase of residence length from 0.3 to $0.9 \mathrm{~m}$.

- For the samples of 700 and $800 \mu \mathrm{m}$, the yields of solid residue significantly decrease from 36 to $10 \mathrm{w} \%$ and from 50 to $21 \mathrm{w} \%$ respectively. The yields of gas significantly increase from 42 to $71 \mathrm{w} \%$ and from 37 to $59 \mathrm{w} \%$ respectively. This indicates that wood devolatilization is still in progress with the increase of residence length from 0.3 to $0.9 \mathrm{~m}$.

These results show the influence of particle size on the apparent pyrolysis kinetics under the explored conditions of temperature and external heat flux. The decrease of pyrolysis progress with the increase of solid initial size illustrates that heat transfer plays an important role on the apparent pyrolysis rate for wood particles between 500 and $800 \mu \mathrm{m}$.

Secondly, the influence of particle size on the mass yields of solid residue, total gas and tar at the end of pyrolysis can be analyzed from the results at $950^{\circ} \mathrm{C}$, as given in Fig. $2 \mathrm{~b}$. Indeed, it can be seen that at $950{ }^{\circ} \mathrm{C}$ and at a residence length of $0.9 \mathrm{~m}$, solid, gas and tar yields are almost the same for all samples. This indicates that pyrolysis is almost finished for all the samples at $950{ }^{\circ} \mathrm{C}$ when passing $0.9 \mathrm{~m}$ in DTR, and also that particle size does not have any significant influence on the final yields of solid, gas and tar at the end of pyrolysis.

Finally, the comparison between Fig. $2 \mathrm{a}$ and $\mathrm{b}$ shows the influence of temperature on both pyrolysis apparent kinetics and the yields of solid residue, gas and tar at the end of pyrolysis.

- The comparison of the results obtained with the sample of $350 \mu \mathrm{m}$ shows that under the conditions explored, the increase of temperature from $800^{\circ} \mathrm{C}$ to $950^{\circ} \mathrm{C}$ has very little influence on the final yields of solid, gas and tar.

- The comparison of the results obtained with the samples of 700 and $800 \mu \mathrm{m}$ shows that under the conditions explored, the increase of temperature from $800^{\circ} \mathrm{C}$ to $950{ }^{\circ} \mathrm{C}$ logically increases the apparent pyrolysis rate.

\subsection{Solid size evolution and morphology}

It can be seen in Fig. 3a and $\mathrm{b}$ that with the pyrolysis progress, the average equivalent spherical diameter decreases for all samples at both $800^{\circ} \mathrm{C}$ and $950{ }^{\circ} \mathrm{C}$. Moreover, the solid size evolution 


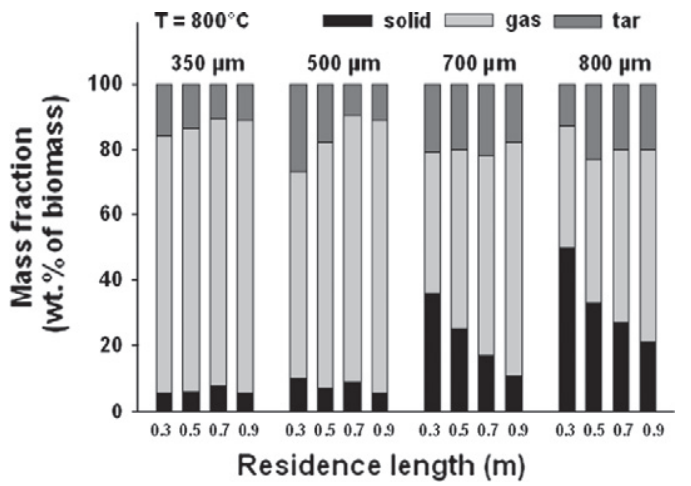

(a) Evolution of mass yields of solid residue, gas and tar during pyrolysis at $800^{\circ} \mathrm{C}$

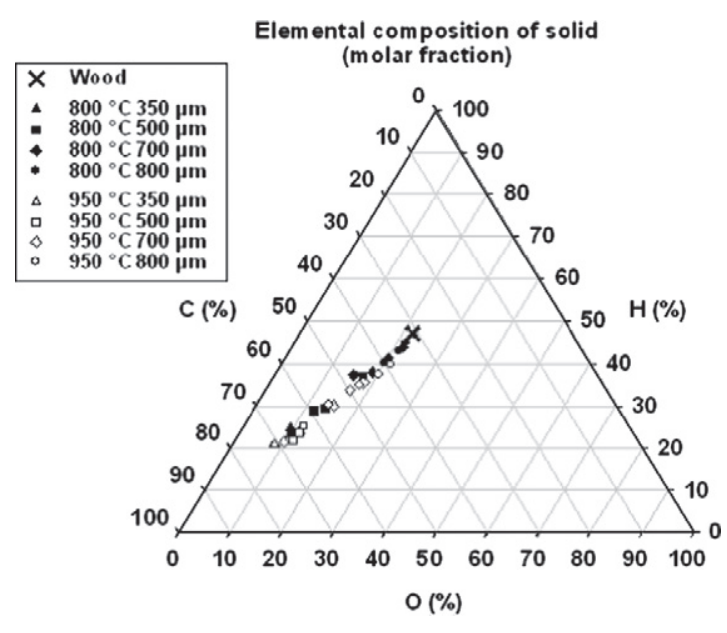

(c) Evolution of elemental composition of solid residue

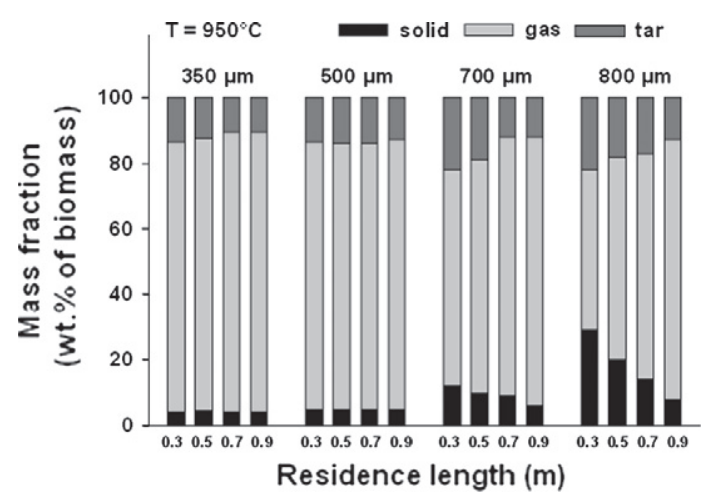

(b) Evolution of mass yields of solid residue, gas and tar during pyrolysis at $950^{\circ} \mathrm{C}$

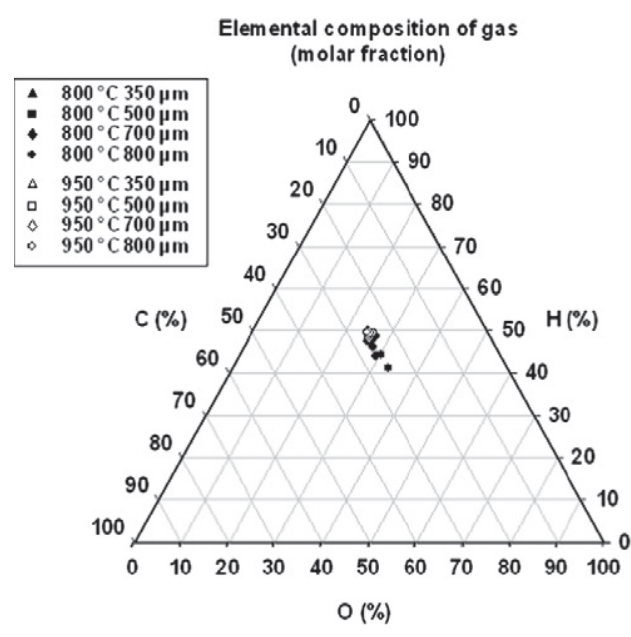

(d) Evolution of elemental composition of produced gas

Fig. 2. Evolution of products mass yields and elemental compositions during pyrolysis.

is qualitatively in accordance with the evolution of the solid mass yield shown in Fig. 2a and b:

- For the samples of 350 and $500 \mu \mathrm{m}$, there is no more decrease of the particle size after a residence length of $0.3 \mathrm{~m}$, as the devolatilization is already finished.

- For the samples of 700 and $800 \mu \mathrm{m}$, the decrease of the particle size is still in progress with the increase of the residence length from 0.3 to $0.9 \mathrm{~m}$, as the devolatilization is in progress.

The previous pyrolysis results showed that at $950{ }^{\circ} \mathrm{C}$ and at a residence length of $0.9 \mathrm{~m}$, the solid devolatilization was almost finished for all the samples. The equivalent spherical diameter of solid residues obtained under these conditions corresponds therefore to the char equivalent diameter at the end of pyrolysis.

The shrinkage factor $S F$ is defined as the ratio between the equivalent spherical diameter of char at the end of pyrolysis and that of wood before pyrolysis. Based on Fig. 3b, it can be estimated as about 0.75 for the sample of $350 \mu \mathrm{m}$ and as about 0.6 for the samples of 500,700 , and $800 \mu \mathrm{m}$ under the conditions explored. This indicates that shrinkage does not only happen in a significant way during fast pyrolysis on particles larger than $10 \mathrm{~mm}[17,18]$, but also on sub-millimetric particles.

Besides, as can be seen in Fig. 4, the initial particle size has a significant influence on char structure at the end of pyrolysis. The char from the sample of $350 \mu \mathrm{m}$ is mainly constituted of exploded porous spheres and to a less extent of fibrous particles. On the contrary, the char from the sample $800 \mu \mathrm{m}$ is only formed of fibrous particles, whose structure is quite similar to that of initial wood, and for the intermediate samples (500 and $700 \mu \mathrm{m}$ ), the situation is intermediate, with mainly fibrous particles. These results tend to confirm the role of heat transfer during pyrolysis for wood particles between 500 and $800 \mu \mathrm{m}$. Indeed, for the largest particles studied, the internal heat transfer limitation must slow down the reaction; the volatiles are then released more slowly and can escape without destroying the solid structure.

\subsection{Elemental composition of solid and dry gas}

As shown in Fig. 2c, before pyrolysis, the molar fractions of $\mathrm{C}, \mathrm{H}$ and $\mathrm{O}$ of virgin wood are of $32 \%, 47 \%$ and $21 \%$ respectively. At the end of pyrolysis, the corresponding points are located at the left bottom in the diagram, giving almost the same value of $\mathrm{C}, \mathrm{H}$ and O - $67 \%, 21 \%$ and $12 \%$ respectively - whatever the initial sample size and pyrolysis temperature. This means that under the conditions studied, at the end of pyrolysis, neither temperature nor particle size has a significant influence on the final solid elemental composition. In average, the chemical formula of the char may be written as $\mathrm{C}_{6} \mathrm{H}_{1.8} \mathrm{O}_{1.0}$. 
(a)

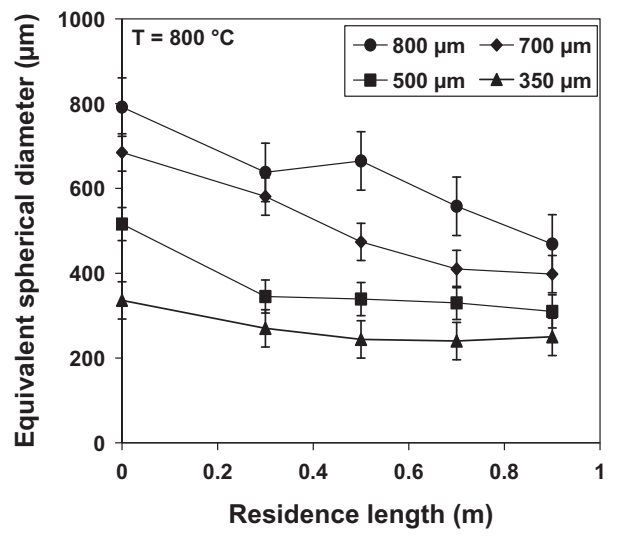

(b)

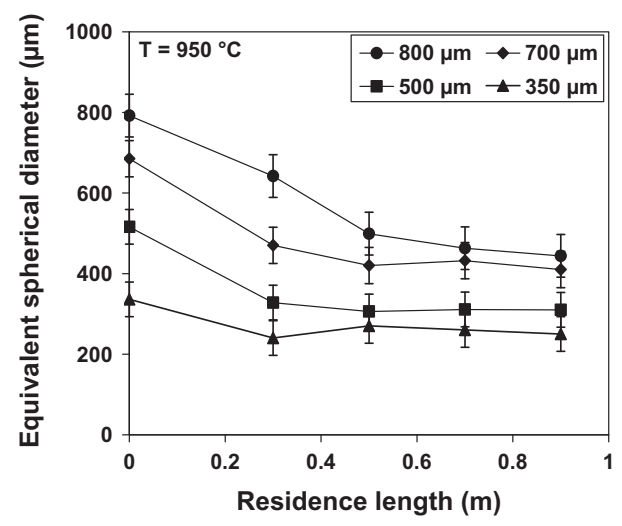

Fig. 3. Measured size of wood and residue samples obtained at (a) $800{ }^{\circ} \mathrm{C}$ and (b) $950{ }^{\circ} \mathrm{C}$.

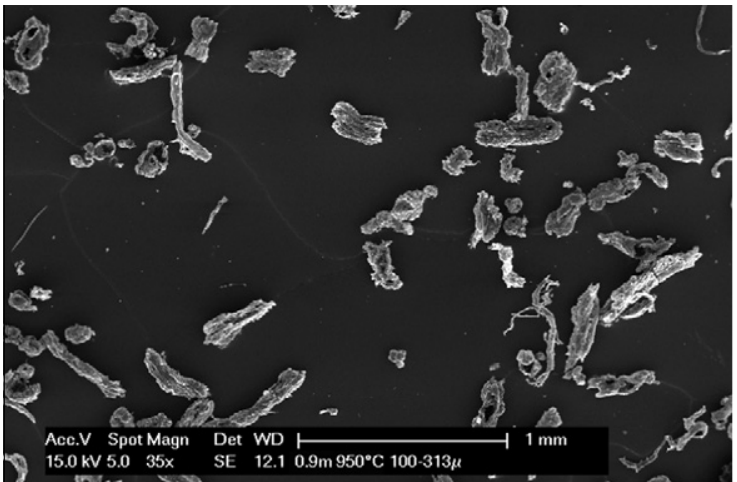

(a)

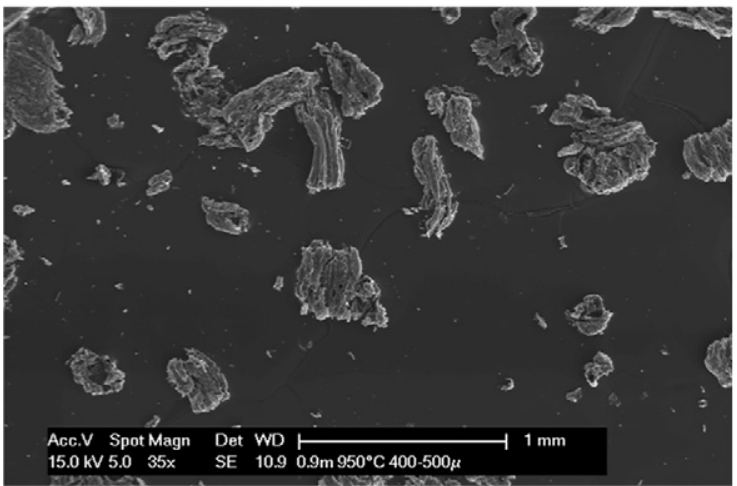

(b)

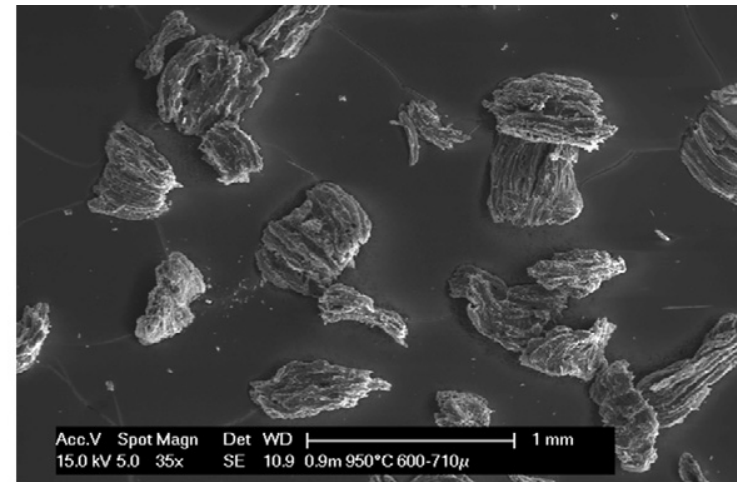

(c)

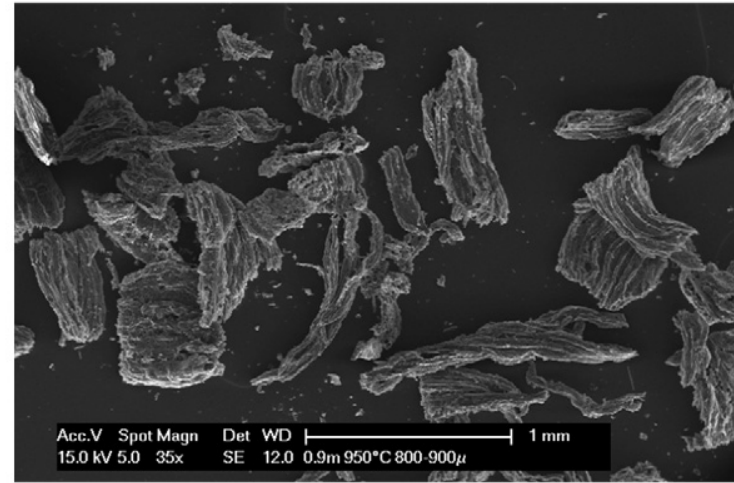

(d)

Fig. 4. SEM observations of chars obtained at $950{ }^{\circ} \mathrm{C}$ after $0.9 \mathrm{~m}$ for particles of: (a) $350 \mu \mathrm{m}$, (b) $500 \mu \mathrm{m}$, (c) $700 \mu \mathrm{m}$ and (d) $800 \mu \mathrm{m}$.

Besides, it can be seen that all the points representing the solid elemental composition along pyrolysis are found in the same straight line which connects the solid composition before pyrolysis (virgin wood) and the solid composition when pyrolysis is finished. Since the solid mass loss is equal to the mass of produced volatiles, a linear evolution in the elemental composition of solid residue indicates that the released volatiles keep the same elemental composition all along pyrolysis progress, whatever the initial particle size and reaction temperature.

Volatiles are composed of gas and tar; it is interesting to investigate the evolution of gas elemental composition during pyrolysis in order to indirectly investigate the evolution of tar elemental composition. The elemental composition of gas is shown in Fig. 2d. It is based on the yields of individual gaseous species including the contribution of water vapor. Note that the trend is similar for the dry gas composition: the gas elemental composition remains almost constant along pyrolysis whatever the initial sample size and the temperature under the conditions explored. The previous results on gas yield showed that at $800^{\circ} \mathrm{C}$, for the samples larger than $350 \mu \mathrm{m}$, the cracking reactions took place when the residence length increased from 0.3 to $0.9 \mathrm{~m}$. This means that at $800{ }^{\circ} \mathrm{C}$, for these samples, the tar cracking reactions contribute to increase the gas amount but let the gas elemental composition unchanged. 


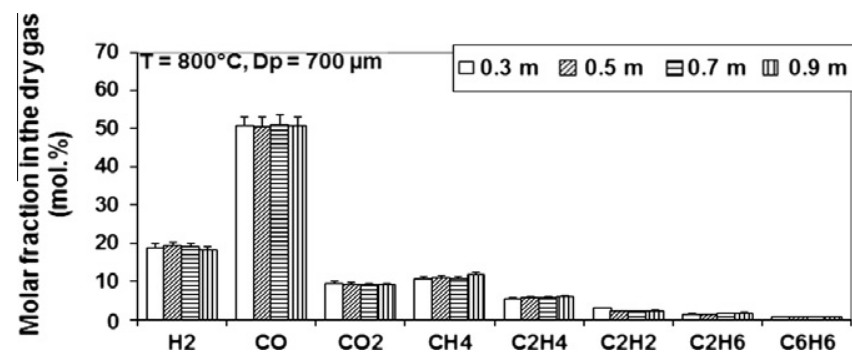

Fig. 5. Evolution of gas composition for sample of $700 \mu \mathrm{m}$ at $800{ }^{\circ} \mathrm{C}$.

\subsection{Gas composition}

It is interesting to investigate whether the constant elemental composition of the produced gas results from a constant composition of the gaseous species. The evolution of gas composition of the sample of $700 \mu \mathrm{m}$ at $800^{\circ} \mathrm{C}$ is given in Fig. 5 as an example to investigate the gas composition versus residence length. It can be seen that with the increase of the residence length from 0.3 to $0.9 \mathrm{~m}$, the dry gas composition remains almost constant along pyrolysis. This observation is also valid for the other samples at the two temperatures, except for the sample of $800 \mu \mathrm{m}$ at $800^{\circ} \mathrm{C}$, which exhibits slight differences at the very beginning of pyrolysis. As can be seen in Fig. 6, more oxygen-containing species (such as $\mathrm{CO}$ and $\mathrm{CO}_{2}$ ) are produced at the very early stage of the pyrolysis, and at the later stages more hydrogen-containing species, such as $\mathrm{H}_{2}$ and $\mathrm{CH}_{4}$, are produced.

At $950^{\circ} \mathrm{C}$ and for a residence length of $0.9 \mathrm{~m}$, the pyrolysis can be considered as nearly finished. It can be seen in Fig. 7 that under these conditions the initial particle size does not have any influence on gas composition.

Comparing the results corresponding to a residence length of $0.9 \mathrm{~m}$ obtained on the sample of $700 \mu \mathrm{m}$ at $800{ }^{\circ} \mathrm{C}$ (Fig. 5) and at $950^{\circ} \mathrm{C}$ (Fig. 7) shows that the increase of temperature mainly increases the proportion of $\mathrm{H}_{2}$ and $\mathrm{C}_{2} \mathrm{H}_{2}$ in gas. The effect of temperature is found to be the same for all the samples, and is in

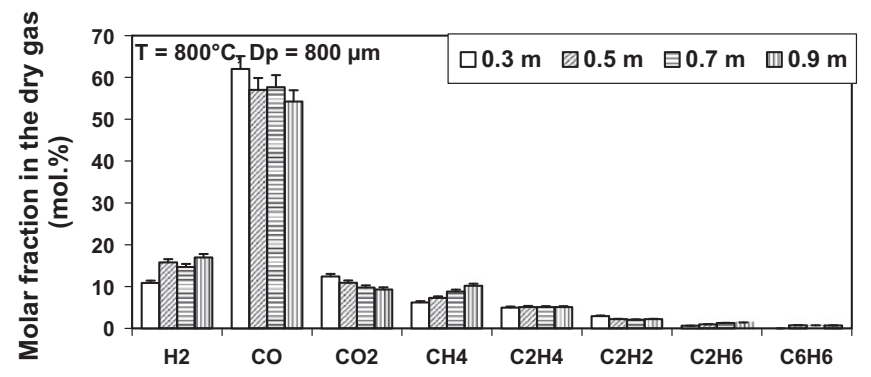

Fig. 6. Evolution of gas composition for sample of $800 \mu \mathrm{m}$ at $800{ }^{\circ} \mathrm{C}$.

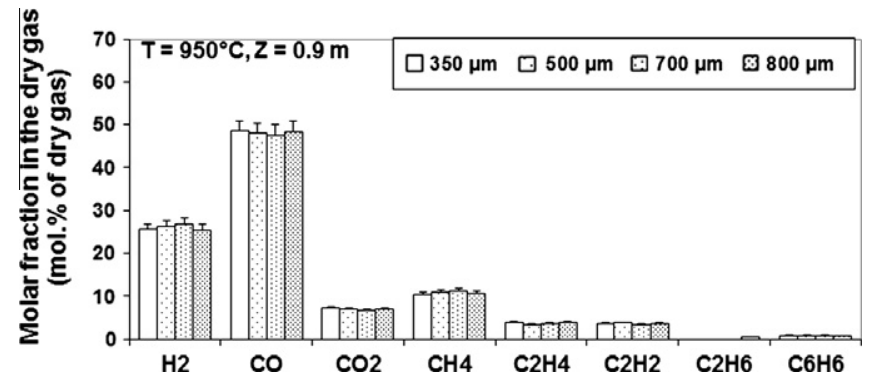

Fig. 7. Gas composition at $950{ }^{\circ} \mathrm{C}$ and $0.9 \mathrm{~m}$ versus particle size. agreement with previous results $[4,19,20]$. This increase of $\mathrm{H}_{2}$ and $\mathrm{C}_{2} \mathrm{H}_{2}$ amounts is supposed to mainly come from the cracking reactions of tar and other $\mathrm{C}_{2}$ species, namely $\mathrm{C}_{2} \mathrm{H}_{4}$ and $\mathrm{C}_{2} \mathrm{H}_{6}$.

\section{Conclusions}

The pyrolysis progress of free-falling wood particles of different sizes was experimentally studied along a $1 \mathrm{~m}$-height zone at temperatures of $800^{\circ} \mathrm{C}$ and $950{ }^{\circ} \mathrm{C}$.

The smallest particles $(350 \mu \mathrm{m})$ appear to be completely pyrolyzed after $0.1 \mathrm{~m}$ of fall while the conversion is still on-going after $0.9 \mathrm{~m}$ for the largest particles $(800 \mu \mathrm{m})$. The structure of the smallest particles seems to suffer drastic changes while the largest ones remain fibrous. Whatever their initial diameter, the particles undergo significant shrinkage. Their final char, gas and tar yields remain the same and are only slightly influenced by the increase of temperature from $800{ }^{\circ} \mathrm{C}$ to $950^{\circ} \mathrm{C}$. Char, gas and tar mass yields go toward about $5 \mathrm{w} \%, 83 \mathrm{w} \%$ and $12 \mathrm{w} \%$ respectively. Along pyrolysis, the elemental composition of the released gas remains constant.

These results confirm that it is necessary to describe the coupled phenomena of heat transfers, chemical reactions and particle properties evolution to predict the time conversion of particles between 350 and $800 \mu \mathrm{m}$ under the conditions of temperature explored.

\section{References}

[1] Di Blasi C. Modeling chemical and physical processes of wood and biomass pyrolysis. Prog Energy Combust Sci 2008;34(1):47-90.

[2] Encinar JM et al. Pyrolysis of two agricultural residues: olive and grape bagasse. Influence of particle size and temperature. Biomass Bioenergy 1996;11(5):397-409.

[3] De Jong W et al. TG-FTIR pyrolysis of coal and secondary biomass fuels: determination of pyrolysis kinetic parameters for main species and NOx precursors. Fuel 2007;86(15):2367-76.

[4] Zanzi R et al. Rapid high-temperature pyrolysis of biomass in a free-fall reactor. Fuel 1996;75(5):545-50.

[5] Zanzi R et al. Rapid pyrolysis of agricultural residues at high temperature. Biomass Bioenergy 2002;23(5):357-66.

[6] Li S et al. Fast pyrolysis of biomass in free-fall reactor for hydrogen-rich gas. Fuel Process Technol 2004;85(8-10):1201-11.

[7] Wei L et al. Characteristics of fast pyrolysis of biomass in a free fall reactor. Fuel Process Technol 2006;87(10):863-71.

[8] Zhang Y et al. Peculiarities of rapid pyrolysis of biomass covering medium- and high-temperature ranges. Energy Fuels 2006;20(6):2705-12.

[9] Dupont $C$ et al. Biomass pyrolysis experiments in an analytical entrained flow reactor between $1073 \mathrm{~K}$ and $1273 \mathrm{~K}$. Fuel 2008;87(7):1155-64.

[10] Couhert $C$ et al. Is it possible to predict gas yields of any biomass after rapid pyrolysis at high temperature from its composition in cellulose, hemicellulose and lignin? Fuel 2009;88(3):408-17.

[11] Yu Q et al. Temperature impact on the formation of tar from biomass pyrolysis in a free-fall reactor. J Anal Appl Pyrol 1997;40-41:481-9.

[12] Bharadwaj $A$ et al. Effects of intraparticle heat and mass transfer on biomass devolatilization: experimental results and model predictions. Energy Fuels 2004;18(4):1021-31.

[13] Dall'Ora $M$ et al. Suspension combustion of wood: Influence of pyrolysis conditions on char yield, morphology, and reactivity. Energy Fuels 2008;22(5):2955-62.

14] Van de Steene L. Thermochimie de la combustion à basses températures de solides pulvérisés: application à un charbon. Institut National Polytechnique de Toulouse; 1999.

[15] Commandré J-M. Formation des oxydes d'azote lors de la combustion de cokes de pétrole dans des conditions de précalcinateur de cimenterie. Institut National Polytechnique de Toulouse; 2002.

[16] Zanzi R. Pyrolysis of biomass: rapid pyrolysis at high temperature; slow pyrolysis for active carbon preparation. Royal Institute of Technology; 2001.

[17] Gronli MG. A theoretical and experimental study of the thermal degradation of biomass. The Norwegian University of Science and Technology; 1996.

[18] Hastaoglu MA, Berruti F. A gas-solid reaction model for flash wood pyrolysis. Fuel 1989;68(11):1408-15.

[19] Nunn TR et al. Product compositions and kinetics in the rapid pyrolysis of sweet gum hardwood. Ind Eng Chem Process Des Dev 1985;24(3):836-44.

[20] Dupont C. Vapogazéification de la biomasse: contribution à l'etude de la phénoménologie entre $800^{\circ} \mathrm{C}$ et $1000^{\circ} \mathrm{C}$. Université Claude Bernard - Lyon 1; 2006. 